\title{
Relationship between Amylose Content and Glycemic Index of Commonly Consumed White Rice
}

\author{
Subramaniam Jeevetha ${ }^{1}$, Mohd Yusof Barakatun-Nisak ${ }^{1}$, \\ Hui-Beng Ngan, Amin Ismail ${ }^{1}$ and Azrina Azlan ${ }^{1}$ \\ ${ }^{1}$ (Department of Nutrition and Dietetics, Faculty of Medicine and Health Sciences, Universiti Putra Malaysia)
}

\begin{abstract}
This study was conducted to analyze the amylose content of two types of white rice commonly consumed by Malaysians and determine its relationship with the glycemic index (GI) value. The two samples of rice namely White Rice 5\% Broken (WR5\%) and Fragrant White Rice (FWR). Nutrient compositions of the rice were analyzed. Amylose content of the rice was determined using colorimetric assay. The GI values of the rice were determined using a standardized protocol. Both types of rice had comparable nutrient composition. The

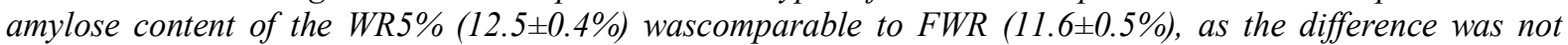

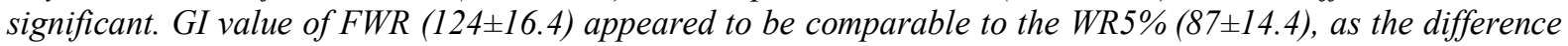
was not significant. This study may show that white rice categorized as lowamylose may have high GI value.
\end{abstract}

Key words: Amylose content, Glycemic Index, white rice

\section{Introduction}

The traditional diets of many Asian countries are predominantly based on polished white rice. In Malaysia for example, rice is consumed daily by almost $97 \%$ of the population particularly in the form of white rice (Norimah et al., 2008). Recently, there has been considerable renewed interest on the significant positive association between rice consumption and risk of type 2 diabetes especially in Asian populations (Hu et al., 2012). This could be due to the high glycemic index value of the polished white rice compared to the whole grain rice $(\mathrm{Hu} 2011)$.

The glycemic index (GI) is a method used to classify dietary carbohydrates based on their impact to the blood glucose response usually 2-hours after meals (Wolever, 2006). A lower diet GI may results in a slower rate of digestion and absorption, hence reducing the rapid elevation of postprandial hyperglycemia as well as insulin concentration which will then influence the management of diabetes (Yusof et al. 2009). GI values of the rice are determined experimentally by feeding 10-12 fasted human subjects a fixed portion of the foods and subsequently measuring samples of their blood at specific intervals of time (Wolever 2006). This procedure is relatively expensive and time-consuming. Besides, numerous factors influence the GI classification including the amylose content of the rice (Brand-Miller et al, 1992).

Amylose, a long straight starch molecule that does not gelatinize during cooking is considered a major determinant of rice appearance and cooking quality. Hence, rice with more amylose content tends to cook fluffy and non-sticky. As previously mentioned, amylose content of the rice influences the GI value where rice that is high in amylose usually has lower GI value (Brand-Miller et al., 1992). This could be due to the formation of complexes between amylose and lipids upon heating, thus making them less accessible to enzymatic digestion which results in a slower rate of digestion (Frei et al., 2003).

Thus, identifying the value of amylose in rice is an alternative inexpensive and less-time consuming strategy for screening and predicting the glycemic response and GI value of the rice. Previous studies in correlating the amylose content of the rice and its GI values have shown conflicting results (Frei et al., 2003; Hu et al., 2004; NikShanita et al., 2011). Indeed, they were particularly focusing on their own locally grown rice in the respective countries (Suwannaporn et al., 2007; Aoki et al., 2006; Okamoto et al., 2009; Otegbayo et al., 2001). It is important to note that white rice has a large variation in GI values ranging from 47 to 112 which is probably due to the inherent botanical differences from various countries (Foster-Powell et al., 2002).

The present study was designed to analyze the amylose content of two types of white rice commonly consumed by Malaysians and determine its relationship with GI values. We hypothesized that the rice with more amylose content would have reduced glycemic responses and demonstrate lower GI values than the rice with less amylose.

\subsection{Sample selection and Preparation}

\section{Materials and Methods}

The two rice samples namely White Rice with 5\% broken grains (WR5\%) and Fragrant White Rice (FWR) were selected based on a previous survey on white rice commonly consumed by Malaysians (Ngan, 
2012). The rice samples for nutritional composition determination was cooked in a rice cooker (FRC 3018SS, FABER, Malaysia Sdn. Bhd.) based on the cooking instructions given by the manufacturer and were stored in a freezer at $-80{ }^{\circ} \mathrm{C}$ until used.The samples were then freeze-dried for four days in freeze dryer (Virtis Company Inc., Gardiner, New York, USA) and ground into fine powder.

Sample preparation for amylose content determination was based on the method described in Vasathan et al. (2001). Raw rice was cleaned, dried and ground using a dry grinder (Blender 8011S, Model HGB2WTS3, Waring Commercial, Connecticut). Lipids were extracted from the grounded sample with $150 \mathrm{ml}$ petroleum ether at $85^{\circ} \mathrm{C}$ on a heating mantle for 7 hours in a Soxhlet extractor. The thimble containing the lipid-free starch was then air dried for 30 minutes and then dried in an oven (MemmertGmbh and Co., Bayern, Germany) overnight at $40^{\circ} \mathrm{C}$ (Hoover and Ratnayake, 2001).

\subsection{Sample analyses}

\subsubsection{Proximate analysis}

The proximate analysis (moisture, ash, protein, fat content) of the cooked rice was analyzed based on the AOAC method (2000), except for total available carbohydrate which was assessed using Clegg Anthrone method (Clegg, 1956). The moisture content was analyzed using the oven drying method, ash content was analyzed using the dry ashing method, the protein content was determined using the Kjeldahl method, while the fat content was analyzed using the Soxtec method.

\subsubsection{Amylose content analyses and calculation}

Amylose content was analyzed using the method described by Juliano et al. (1981). In brief, rice powder $(100 \mathrm{~g})$ was mixed with $1 \mathrm{ml}$ of $95 \%$ ethanol and $9 \mathrm{ml}$ of $1 \mathrm{M} \mathrm{NaOH}$ in a $100 \mathrm{ml}$ beaker and was left overnight. On the subsequent day, distilled water was added to the mixture to make up the final volume to 100 $\mathrm{ml}$. A sample of $5 \mathrm{ml}$ of the mixed solution was measured into a volumetric flask, $1 \mathrm{ml}$ of $1 \mathrm{M}$ acetic acid and 2 $\mathrm{ml}$ iodine solution were added into the solution and the volume made up to $100 \mathrm{ml}$ with distilled water. The contents were stirred and allowed to stand for 20 minutes before absorbance was measured at $620 \mathrm{~nm}$ with a UV-Spectrophotometer (UV 1601-Spectrophotometer, Shimadzu Corporation, Kyoto, Japan). The amylose content of the rice samples were calculated based on the method described by McGrance et al. (1998) using a standard curve plotted from absorbance of amylose standards. Amylopectin content of the rice samples was calculated by the difference based on Juan et al. (2006)using the following equation;

$$
\text { Amylopectin (\%) }=100 \%-\text { amylose }(\%)
$$

These values were used to classify the rice based on their amylose content (Juliano, 1971) (Table 1). The amylose to amylopectin ratio was also calculated.

Table 1: Amylose content (\%) category

\begin{tabular}{ll}
\hline Amylose content (\%) & Category \\
\hline $1-2$ & Waxy \\
$2-9$ & Very low amylose \\
$10-20$ & Low \\
$20-25$ & Intermediate \\
$25-30$ & High \\
\hline
\end{tabular}

\subsection{Glycemic Index (GI)}

The protocol for GI determination was based on the standardized methodology according to the Australian Standard ${ }^{\mathbb{Q}}$ (2007). This was a randomized cross-over, single blinded, experimental study that was approved by UPM Clinical and Research Ethics Committee.

\subsubsection{Subjects' selection}

Subjects were recruited based on their body mass index (BMI) and their fasting capillary blood glucose level. Inclusion criteria included: men or non-pregnant women, aged between 18 to 30 years, normal BMI (19 $24.9 \mathrm{kgm}^{-2}$ ) and with fasting blood glucose of $\leq 5.6 \mathrm{mmol} / 1$ (Bebakar et al., 2009). Subjects who were smoking and taking medications that might affect glucose metabolism were excluded. A total of 11 subjects $(6$ men and 5 women) participated in the study. Their mean age and BMI were $22.6 \pm 1.2$ years and $21.6 \pm 2.1 \mathrm{kgm}^{-}$ ${ }^{2}$ respectively. The purpose and protocol of the study were explained to the subjects and their written consent was obtained. 


\subsubsection{Test meal preparation and study protocol}

The two samples of the rice were prepared according to the method previously described (BarakatunNisak et al., 2005). Glucose (Glucolin ${ }^{\circledR}$, Thailand) was used as reference food and it was prepared by dissolving in $250 \mathrm{ml}$ of water. Both of the test rice (Table 2) and reference food (Glucolin ${ }^{\circledR}$, Thailand) were served to provide $25 \mathrm{~g}$ available carbohydrate.

Table 2: Amount of cooked white rice consumed by subjects in the Glycemic Index test

\begin{tabular}{|c|c|c|}
\hline Type of rice & $\begin{array}{l}\text { Total available carbohydrate } \\
\text { (per } 100 \mathrm{~g} \text { of rice) }\end{array}$ & $\begin{array}{l}\text { Weight (g) of cooked white rice based on } \\
25 \mathrm{~g} \text { total available carbohydrate }\end{array}$ \\
\hline $\begin{array}{l}\text { Fragrant White Rice (FWR) } \\
\end{array}$ & 24.30 & 102.87 \\
\hline White Rice 5\% Broken (WR5\%) & 27.52 & 90.85 \\
\hline
\end{tabular}

Subjects were required to participate in five separate occasions (one test for each type of test rice and three repeated tests with reference food) of the study protocol, which were carried out in the morning after 10 $12 \mathrm{~h}$ overnight fasting. Subjects were also advised to maintain their usual diet and physical activity level throughout the study period. In the morning of the test, subjects were randomized to consume either the test rice with $250 \mathrm{ml}$ plain water or the glucose solution as a reference food. After duplicate fasting blood glucose samples were taken, and subjects were required to consume the reference food or the test rice at a comfortable pace within 15 minutes after the meal began. Subsequent blood samples were taken at 15, 30, 45, 60, 90 and 120 minutes. The tests were performed approximately a week apart and started at the same time in the morning.

\subsubsection{Blood glucose analyses and Glycemic Index calculation}

A total of $150 \mathrm{uL}$ of whole blood samples were obtained by finger-prick with a lancet (Homocue Safety Lancet ${ }^{\circledR}$ USA) and collected into a $0.25 \mathrm{ml}$ Glucose tube (MiniCollect, Greiner Bio-One, Germany). Blood samples were centrifuged and the plasma was immediately stored at $-20{ }^{\circ} \mathrm{C}$ for future analyses. Plasma glucose was assayed using an automatic glucose analyzer (YSI 2300 STAT Life Sciences, Yellow Spring, Ohio USA) which was based on the glucose oxidase method.

The GI value of the rice samples was calculated based on the method described by Wolever (2006). The blood glucose responses for every point of time over 2-hours were used to calculate the incremental area under the curve (iAUC) for the test rice samples and reference food, ignoring the area beneath the baseline (Australian Standard $\left.{ }^{\circledR}, 2007\right)$. Data were entered into the Lotus software (123, CA USA). The subject's GI was the percentage between the iAUC of the test rice and the mean iAUC of the three repeated glucose test. The GI of each type of rice was taken as the average of all individuals values. The calculation for GI was as follows (Wolever et al., 2006):

$$
\mathrm{GI}=\underset{\text { Mean iAUC of reference food }}{\mathrm{iAUC} \text { of test rice }} \times 100
$$

The study used a previous describe method and classified the food as high (GI $>69)$, medium (GI $=56$ 69) and low (GI<56) GI (Wolever 2006).

\subsection{Statistical analyses}

Data were analyzed using SPSS version 20.0 software (SPSS Inc., Chicago IL). Results are expressed as mean \pm standard deviation (SD) unless otherwise indicated. Mean differences between the two types of rice was analyzed using Independent T-Test.

\section{Results}

\subsection{Proximate and amylose content analyses}

The WR5\% samples contained higher amounts of ash, fat, protein and available carbohydrates than the FWR (Table 3). However, the differences were not statistically significant $(\mathrm{p}>0.05)$. 
Table 3: The nutrient contents in $100 \mathrm{~g}$ of rice sample

\begin{tabular}{llllll}
\hline Type of rice & $\begin{array}{l}\text { Moisture } \\
\text { content } \\
\text { (g) }\end{array}$ & $\begin{array}{l}\text { Ash content } \\
\text { (g) }\end{array}$ & $\begin{array}{l}\text { Fat content } \\
\text { (g) }\end{array}$ & $\begin{array}{l}\text { Protein content } \\
\text { (g) }\end{array}$ & $\begin{array}{l}\text { Total } \\
\text { available } \\
\text { CHO } \\
\text { (g) }\end{array}$ \\
\hline $\begin{array}{l}\text { Fragrant White } \\
\text { Rice (FWR) }\end{array}$ & 53.071 & 0.120 & 3.096 & 3.705 & 24.30 \\
$\begin{array}{l}\text { White Rice 5\% } \\
\text { Broken (WR5\%) }\end{array}$ & 51.608 & 0.150 & 5.040 & 3.897 & 27.52 \\
\hline
\end{tabular}

The amylose content of WR5\% $(12.5 \pm 0.4 \%)$ and FWR $(11.6 \pm 0.5 \%)$ were comparable $(\mathrm{p}>0.05)$ (Table 4). The FWR had comparable amylopectin content $(88.4 \pm 0.5 \%)$ with the WR5\% $(87.5 \pm$ $0.4 \%)(\mathrm{p}>0.05)$.

Table 4: Amylose content and Glycemic Index value of tested White Rice

\begin{tabular}{|c|c|c|c|c|}
\hline Type of rice & $\begin{array}{l}\text { Amylose } \\
\text { content (\%) }\end{array}$ & Amylopectin (\%) & $\begin{array}{l}\text { Ratio of amylose: } \\
\text { amylopectin }\end{array}$ & GI value \\
\hline $\begin{array}{lll}\text { Fragrant } & \text { White } & \text { Rice } \\
\text { (FWR) } & & \end{array}$ & $11.6 \pm 0.5$ & $88.4 \pm 0.5$ & $0.13 \pm 0.005$ & $124.2 \pm 16.4$ \\
\hline $\begin{array}{l}\text { White Rice 5\% Broken } \\
\text { (WR5\%) }\end{array}$ & $12.5 \pm 0.4$ & $87.5 \pm 0.4$ & $0.14 \pm 0.004$ & $87.3 \pm 14.4$ \\
\hline
\end{tabular}

The ratio of total amylose to amylopectin for FWR $(0.13 \pm 0.005)$ was comparable with WR5\% $(0.14 \pm$ $0.004)(p>0.05)$. Both types of rice were classified as low in amylose (Juliano, 1971).

\subsection{Blood glucose and Glycemic Index}

Out of the total of 11 subjects recruited, of whom three were excluded from the data analysis as their coefficient variation (CV) of reference test (refCV) was more than 30\% (Wolever et al., 2006). Table 5 shows the mean values of iAUC for the three reference tests and the refCV for each particular subject.

Table 5: The mean \pm SEM and the coefficient variation for individual subjects for the three glucose reference tests

\begin{tabular}{lll}
\hline Subject & Mean \pm SEM & refCV (\%) \\
\hline 1 & $256.41 \pm 7.52$ & 2.93 \\
2 & $377.14 \pm 74.54$ & 19.76 \\
3 & $141.16 \pm 30.59$ & 21.67 \\
4 & $165.81 \pm 77.50$ & $46.73^{*}$ \\
5 & $124.97 \pm 24.34$ & 19.48 \\
6 & $141.31 \pm 32.684$ & 23.13 \\
7 & $144.47 \pm 51.43$ & $35.60^{*}$ \\
8 & $139.60 \pm 13.11$ & 9.39 \\
9 & $102.06 \pm 21.82$ & 21.38 \\
10 & $125.36 \pm 41.52$ & $33.12^{*}$ \\
11 & $98.77 \pm 6.204$ & 6.28 \\
\hline the CV $>30 \%$. & &
\end{tabular}

Subjects number 4, 7 and 10 were excluded from the data analysis as theoretically, large variability of glycemic response area will result in skewed distribution of GI values (Wolever et al., 1991). Although the standard food was consumed under standardized conditions, day-to-day variation of the glycemic response to glucose will occur within the same subjects too.

The GI of the reference food (glucose) was assigned a value of GI=100 (Brand-Miller et al., 1992). The GI value of the FWR (GI = $124 \pm 16.4$ ) was comparable with WR5\% (87.3 \pm 14.4$)$ (Table 4), as the differences were not statistically significant $(\mathrm{p}>0.05)$. 


\section{Discussion}

This present study was conducted to determine the amylose content of the two types of white rice that commonly consumed by Malaysian and its relationship with GI value. Based on the accepted classifications, our results showed that both the FWR and WR5\% can be categorized as low amylose (Juliano, 1971) and high GI rice (Wolever, 2006).

The amylose content of WR5\% and FWR in this study was lower than the specific white rice grown locally which was reported to contain $26 \%$ of amylose (Musa et al. 2011), but was comparable to the white rice grown in Thailand (15\%) (Sompong et al., 2010). This could be due to the two types of white rice determined in this study were imported from Thailand. Nevertheless, in both studies reported above, the GI values of the white rice were not determined and correlated with their amylose content (Musa et al., 2011; Sompong et al., 2010)

The two types of white rice determined in this study can be categorized as high GI foods. This was consistent with previous studies where white rice were always considered as high GI foods and GI values of more than 80 were typical (Brand-Miller et al., 1992; Barakatun-Nisak et al. 2005). Wide differences in digestibility and GI values of white rice have been ascribed to various factors, including amylose and amylopectin ratio which are important molecules that determine the structure of the rice (Denardin et al., 2012). The structure of the rice can have a profound effect on the rate of digestibility and the response in blood glucose to the rice (Denardin et al., 2012).

White rice is a polysaccharide consisting of long chains of glucose molecules that are linked together in the form of amylose and amylopectin. Amylose consists of a linear molecule while amylopectin is highly branched (Brand-Miller et al. 1992). Rice with high amylose fraction (>28\%) such as Basmati and Doongara brown rice have been shown to produce a lower blood glucose and insulin response (Brand-Miller et al., 1992). In contrast, lower proportion of amylose in rice resulted in a higher blood glucose response than the high amylose rice and is considered a high GI food (Brand-Miller et al;. 1992; Hu et al. 2004). Higher rate of digestion after consuming low amylose rice (or rice high in amylopectin) could be due to the inability of amylopectin molecules to form complexes with compounds such as fatty acids, thus increasing accessibility for a-amylase to the molecules and resulting in easy and quick digestibility (Hu et al. 2004).

Previous studies have shown that there was negative relationship between amylose content and GI value (Brand-Miller et al., 1992; NikShanita et al., 2011). This indicates that rice with low amylose content have high GI value, thus producing high postprandial glucose responses associated with increased risk of metabolic diseases such type 2 diabetes (Barakatun-Nisak et al. 2009). Similar findings were also documented in three main Chinese rice cultivars (Hu et al., 2004), in six indigenous Philippine rice cultivars (Frei et al. 2003), and in several types of foods commonly consumed by Malaysians (NikShanita et al. 2011). Thus, further analysis was done, where statistical analysis was conducted to determine the relationship between amylose: amylopectin ratios and the GI value of the white rice. We noted a non-significant negative relationship between amylose content of the rice and its GI value (Figure 1), and this was consistent with the previous studies. Nonetheless, due to insufficient sample size $(\mathrm{n}=2)$ the relationship does not explain real relationship. The non-significant findings could be due to the minimal amount of amylose that presence in white rice as studies have shown that at least $50 \%$ of amylose content in a food is required to exert significant reduction in plasma glucose (NikShanita et al. 2011)

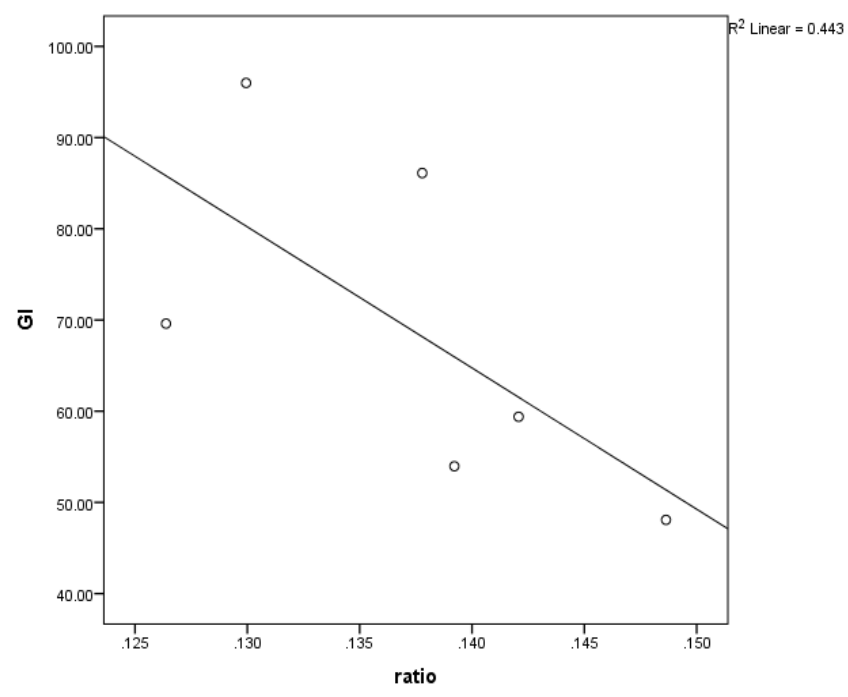

Figure 1: Relationship between amylose: amylopectin ratios and GI values (GI, Glycemic Index) 
We noted that this study was limited to only two types of white rice and the amylose and GI values were comparable. However, the amylose content determinationcan be used as a preliminary step to predict the GI value determination of white rice. Nevertheless, purification techniques prior to amylose content determination must be improved to avoid any reactions that could affect the amylose. Anthrone method used in this study to determine total available carbohydrate has insensitivity to interferences from other cellular components (Dulekgurgen, 2004). Future studies should explore the relationship between the GI values and amylose content of various types of rice that commonly consumed by Malaysians.

\section{Conclusion}

The present study showed that both FWR and WR5\% are categorized as low amylose and high GI white rice. This suggests that white rice with low amylose content may have high GI value, as amylose content have negative relationship withGI value. Understanding of this relationship may be helpful for preliminary prediction of GI values of white rice.

\section{Acknowledgement}

We wish to thank MohdFaez bin Bachok, all the subjects, and the staffs of the Nutrition Laboratory, Faculty of Medicine and Health Sciences, Universiti Putra Malaysia for their participation and assistance in this study. The research was funded by the Research University Grant of Universiti Putra Malaysia (04-01-111161RU).

\section{Declaration of interest}

We have no relevant interest(s) to disclose.

\section{References}

[1]. Aoki N, Umemoto T, Yoshida S, Ishii T, Kamijima O, Matsukura U, Inouchi N. Genetic analysis of long chain synthesis in rice amylopectin. Euphytica. 151, 2006, pp 225-234.

[2]. Barakatun-Nisak MY, Ruzita AT and Norimah AK. Glycemic index of eight types of commercial rice in Malaysia. Malaysian Journal of Nutrition.11(2), 2005, pp. 151-163.

[3]. Barakatun-Nisak MY, Ruzita AT, Norimah AK, Nor Azmi K \& Fatimah A. Acute effect of low and high glycemic index meals on postprandial glycaemia and insulin responses in patients with type 2 diabetes mellitus. Malaysian Journal of Medical and Health Sciences. Volume 5 (1), 2009, pp. 11-20.

[4]. Bebakar WMW, Khir AS, Eu ALK, Zain AZM, Ngan A, Peng CS, et al. Clinical Practice Guidelines: Management of Type 2 Diabetes Mellitus. $4^{\text {th }}$ Edition. Ministry of Health Malaysia. 2009

[5]. Brand-Miller J,Pang E, and Bramall L.Rice: a high or low glycemic index food. American Journal of Clinical Nutrition. 56, 1992, pp 1034-6.

[6]. Clegg KM. The application of the anthrone reagent to the estimation of starch in cereals. Journal of the Science of Food and Agriculture. Volume 7, Issue 1, 1956, pages 40-44.

[7]. Denardin CC, Boufleur N, Reckziegel P, Leila Picolli da Silva, Walter M. Amylose content in rice (Oryza sativa) affects performance, glycemic and lipidic metabolism in rats. Ciência Rural, Santa Maria. 42(2), 2012, pp.381-387.

[8]. Dulekgurgen E. Total Carbohydrates Protocol. 2004. University of Illinois, Urbana Champaign. [Online]. http://web.itu.edu.tr/ dulekgurgen/Carbs.pdf

[9]. Foster-Powell K, Holt SHA, and Brand-Miller JC.International table of glycemic index and glycemic loadvalues: 2002. American Journal of Clinical Nutrition. 76, 2002, pp. 5-56.

[10]. Frei M, Siddhuraju P \& Becker K. Studies on the in vitro starch digestibility and the GI of six different indigenous rice cultivars from the Philippines. Food Chemistry.83, 2003. pp 395-402.

[11]. Hoover, R. and Ratnayake, W.S., Current Protocols in Food Analytical Chemistry, Starch and Starch Derivatives, 2001, E2.3.1E2.3.5

[12]. Hu EA,Pan A, Malik V,Sun Q. White rice consumption and risk of type 2 diabetes: meta-analysis and systematic review.British Medical Journal.344:e1454. 2012.

[13]. Hu FB. Globalization of Diabetes. Diabetes Care. 34, 2011, pp 1249-1257

[14]. Hu P, Zhao H, Duan Z, Linlin Z and Wu D. Starch digestibility and the estimated glycemic score of different types of rice differing in amylose contents. Journal of Cereal Science. 40, 2004, pp. 231-237.

[15]. Juan G, Luis A and David B.. Isolation and molecular characterization of Makal (Xanthosomayucatanensis) starch.Starch.58, 2006, pp. 300-307.

[16]. Juliano BO, Perez CM and Blakeney AB. International Cooperative testing on the amylose content of milled rice. Starch.33(5), 1981, pp. 157-162.

[17]. Juliano BO. A simplified assay for milled rice amylose. Cereal Science Today, 16, 1971, pp. 334-338.

[18]. McGrance SJ, Cornell HJ and Rix CJ. A simple and rapid colorimetric method for the determination of amylose in starch products. Starch.50, 1998, pp. 158-163.

[19]. Musa ASN, Umar IM and Ismail M. Physicochemical properties of germinated brown rice (Oryza sativa L.) starch. African Journal of Biotechnology. Vol. 10(33), 2011, pp. 6281-6291.

[20]. Ngan H.B., Glycemic index values of selected commercialized rice in Malaysia, BSc thesis, Selangor, Universiti Putra Malaysia, Malaysia, 2012.

[21]. Nik-Shanita S, HasnahH,\&KhooCW. Amylose and Amylopectin in Selected Malaysian Foods and its Relationship to Glycemic Index.SainsMalaysiana. 40(8), 2011, pp. 865-870.

[22]. Norimah AK, Safiah M, Jamal K, SitiHaslinda, Zuhaida H, Rohida S, Fatimah S, SitiNorazlin, Poh BK, Kandiah M, Zalilah MS, Wan Manan WM, Fatimah S and Azmi MY., Food Consumption Patterns: Findings from the Malaysian Adult Nutrition Survey (MANS). Malaysian Journal of Nutrition. 14 (1), 2008, pp $25-39$. 
[23]. Official methods of analysis. 17 $7^{\text {th }}$ Edition, Association of Official Analytical Chemists (AOAC) International, Gaithersburg, Maryland. 2000

[24]. Okamoto K, Hirasawa H, Umemoto T. Screening and characterization of cultivar with M-type amylopectin in Japanese upland rice. Breeding Science. 59, 2009, pp. $179-186$.

[25]. Otegbayo BO, Osamuel F, Fashakin JB. Effect of Parboiling on Physio-chemical Qualities of Two Local Rice Varieties in Nigeria. The Journal of Food Technology in Africa. Vol. 6: No 4. 2001

[26]. Sompong R, Siebenhandl-Ehn S, Berghofer E and Schoenlechner R. Extrusion cooking properties of white and colored rice varieties with different amylose content. Starch.63, 2011, pp. 55-63.

[27]. Suwannaporn P, Pitiphunpong S, Champangern S. Classification of Rice Amylose Content by Discriminate Analysis of Physicochemical Properties.Starch.59, 2007, pp. 171-177.

[28]. The Glycemic Index of foods, Australian Standard. 2007. Australia: Standard Australia.

[29]. Vasanthan T. Overview of Laboratory Isolation of Starch from Plant Materials.Current Protocols in Food Analytical Chemistry.2001, E2.1.1 - E2.1.6.

[30]. Wolever TMS. The glycemic index: a physiological classification of dietary carbohydrate. Oxfordshire, CAB International. 2006

[31]. Wolever, T. M. S., Jenkins, D. J. A., Jenkins, A. L., \&Josse, R. G. The glycemic index: methodology and clinical implications. American Journal of Clinical Nutrition, 54, 1991, pp. 846-854.

[32]. Yusof BNM, Talib R, Kamaruddin N, Karim N, Chinna K \& Gilbertson H. A low-GI diet is associated with a short-term improvement of glycaemic control in Asian patients with type 2 diabetes. Diabetes, Obesity and Metabolism. 11, 2009, pp 387-396. 